\title{
Aphasia simulation: A perspective from the student and standardized patient
}

\author{
Suzanne Moineau \\ California State University San Marcos, smoineau@csusm.edu \\ Deb Bennett \\ California State University San Marcos, debennet@csusm.edu \\ Alison Scheer-Cohen \\ California State University San Marcos, ascheer@csusm.edu \\ DOI: doi.org/10.30707/TLCSD2.1Moineau
}

Follow this and additional works at: https://ir.library.illinoisstate.edu/tlcsd

Part of the Communication Sciences and Disorders Commons, Curriculum and Instruction Commons, and the Rehabilitation and Therapy Commons

\section{Recommended Citation}

Moineau, Suzanne; Bennett, Deb; and Scheer-Cohen, Alison (2018) "Aphasia simulation: A perspective from the student and standardized patient," Teaching and Learning in Communication Sciences \& Disorders: Vol. 2: Iss. 1, Article 6. DOI: doi.org/10.30707/TLCSD2.1Moineau

Available at: https://ir.library.illinoisstate.edu/tlcsd/vol2/iss1/6

This Scholarly Teaching is brought to you for free and open access by ISU ReD: Research and eData. It has been accepted for inclusion in Teaching and Learning in Communication Sciences \& Disorders by an authorized editor of ISU ReD: Research and eData. For more information, please contact ISUReD@ilstu.edu. 


\title{
Aphasia simulation: A perspective from the student and standardized patient
}

\begin{abstract}
The aim of the current study was to examine student ability, student and standardized patient perceptions of competency, and student perceptions of effectiveness of simulation methodology for conducting language screenings on individuals with aphasia. Graduate students enrolled in a mandatory course on acquired language disorders $(n=36)$ completed a variety of simulated learning experiences using videos, high-fidelity manikins, and standardized patients, in preparing them for clinical practice with persons with aphasia. 5-point Likert scales and open-ended survey questions relating to student and standardized patients' perceptions were administered. Results demonstrated a strong positive perception that simulation promotes student understanding of assessment procedures and aids in the development of clinical judgment. Data also illuminate that certain skills may be slower to emerge and require greater experience and supervisory feedback, for example, problem-solving difficult moments. There was an overall positive response to the use of simulation methodology to build skills in screening patients with PWA. Students' perceptions matched that of the standardized patients, and students excelled in the final summative skill activity.
\end{abstract}

Keywords: aphasia; simulated learning; academic education; clinical education

\section{Keywords}

aphasia, simulated learning, academic education, clinical education

\section{Cover Page Footnote}

Acknowledgments The authors would like to acknowledge Laura Coca, M.A., CCC-SLP and Kristen Nahrstedt, M.A., CCC-SLP for assisting with supervision, in addition to providing insights and reflections of the simulation experiences. The authors also wish to thank the Cohort 7 graduate students and standardized patients. Materials for the high-fidelity manikin simulation were generously provided by the CSUSM School of Nursing. 


\section{Introduction}

Clinical experiences in speech-language pathology (SLP) are essential for students to develop clinical competencies prior to graduation. Students' clinical skills are developed through active participation, observation, self-evaluation, and feedback in real world workplaces (Hill, Davidson, McAllister, Wright, \& Theodoros, 2014). In the past few years high quality traditional clinical placements in medical facilities have become a challenge for SLP graduate programs to obtain due to new working practices, changes in the healthcare structure, financial constraints, and staff shortages (Read, 2014).

Simulation is a well-known teaching-learning method that attempts to duplicate real life experiences in an artificial environment (Blackburn \& Sadler, 2003; Brannan, White, \& Bezanson, 2008; Decker, Sportsman, Puetz, \& Billings, 2008; Lasater, 2007; Rutherford-Hemming, 2012; Seropian, Dillman, \& Farris, 2007). It has been used across professions, including but not limited to military, aviation, economics, teacher education, medicine, nursing, and SLP. According to Gaba (2004), simulation is a "technique not technology-to replace or amplify real experiences with guided experiences that evoke or replicate substantial aspects of the real world in a full interactive manner" (p. i2). Simulated clinical learning environments are being implemented to provide a safe clinical experience where students are provided the opportunity to practice interprofessional and clinical reasoning skills, while fostering an increase in self-confidence and autonomy, without potential risk to a live patient (Read, 2014). The use of standardized patients has become the common simulated clinical learning environment in the United Kingdom, where students in the health sciences are learning about the complexities of providing care to individuals (Read, 2014).

Simulation methodology started utilizing low-fidelity manikins and has evolved at an extraordinary pace, using high-fidelity manikins and standardized patients (actors) (Levitt-Jones \& Lapkin, 2014). Simulation-based training has been implemented in medicine and nursing for many years. However, simulation-based training is a relatively new methodology for SLP programs (Miles, Friary, Jackson, Sekula, \& Braakhuis, 2016).

As simulation has proven an effective instructional methodology in academic educational settings for healthcare fields (Hill, et al., 2010; Zraick, Allen, \& Johnson, 2003), and the demand for varied clinical placements in healthcare settings (e.g., hospital; private practice; skilled nursing facility) continues to rise (Dudding, 2015), the Council for Clinical Certification (CFCC) in Audiology and Speech-Language Pathology of the American Speech-Language-Hearing Association (ASHA) revised Standard V-B to expand the definition of supervised clinical experiences to include simulation (CFCC, 2013). Standard V-B encompasses the acquisition of knowledge and skills in the prevention, assessment, and treatment of normal and disordered communication across the lifespan. The additional implementation language states, "Alternative clinical experiences may include the use of standardized patients and simulation technologies (e.g., standardized patients, virtual patients, digitized manikins, immersive reality, task trainers, computer-based interactive)" (CFCC, 2013). As such, university educators and professional associations are integrating simulated learning environments into the curriculum (MacBean, Theodoros, Davidson, \& Hill, 2013). As the use of simulation for clinical hours is implemented, the field will benefit from research and systematic study in standards of best practice, including design, outcomes and 
objectives, facilitation, debriefing, and assessment (International Nursing Association for Clinical Simulation and Learning, 2016).

Cook and colleagues (2011) completed a meta-analysis of 609 eligible studies to examine simulation technology in healthcare professions. The review revealed outcomes for student knowledge, skills, and behaviors; as well as, outcomes for patients. None of the 609 studies included in Cook et al.'s (2011) meta-analysis included SLP participants. There are very few studies to date that discuss the use of simulation methodology in training graduate students in SLP. Zraick and colleagues (2003) investigated the use of standardized patients with simulated aphasia to train new graduate SLP students in effective interpersonal communication. Eighteen firstsemester students with no prior experience or exposure to aphasia were divided into two groups. All had classroom lectures on communicating with individuals with aphasia, while half also had exposure to the standardized patients. Findings across both groups revealed competency with the mechanics of performing evaluation tasks; however, significant difficulty with interpersonal communication. While the group with simulation did not outperform those with just classroom instruction, the simulation methodology served to provide valuable insights into student deficits and areas for further training.

Another study by Ward and colleagues (2015) investigated the use of simulated learning environments to develop clinical skills in pediatric dysphagia management. Twenty-nine university students completed four hours of simulation, specifically a feeding assessment and clinical swallow examination, as part of a mandatory swallowing course. In this study, results revealed that students perceived changes in knowledge given content-related lectures. Students perceived changes in skills and confidence following simulation. In addition, students reported a decrease in anxiety about working with patients in clinical placements post-stimulation. Student ratings of their knowledge, skills, and behaviors were low, indicating that additional simulation practice may enhance students' perception of competency.

The purpose of the current study was to assess SLP students' ability to complete a language screening via simulation methodology, examine the students' and standardized patients' perceptions of competency in completing the simulation activity, and to explore the perceived effectiveness of simulation to facilitate skill development. Primarily, the researchers sought to describe student skill assessment, and reflection immediately and 3-months post-simulation experience.

\section{Methodology}

Participants. This study used a descriptive survey design to assess student acquisition and perception of skills in assessment of Persons with Aphasia (PWA). Participants included 36 SLP students in the first semester of a 2-year graduate program leading towards a Master of Science in SLP. All students were enrolled in a mandatory 3-unit course covering language disorders in adults, which used lecture and simulation to teach and develop skills in the assessment and treatment of PWA. None of the students had any prior or concurrent experience in providing direct clinical SLP services to PWA; however, 12 of the 36 students were simultaneously observing services being provided to PWA in the on-campus clinic. These 12 students were shadowing second-year graduate students for approximately three hours per week. The remaining 24 students 
were placed in the local public schools for observation and had no exposure to services being provided to PWA. All of the data collected for this study were part of the regular course assignments. The university's institutional review board committee deemed the work exempt from review and thus students were not required to provide consent for their data to be analyzed as part of this study. Measurements were collected on: 1) student perception of the effectiveness and utility of the high-fidelity manikin simulation to train skills; 2) supervisor scoring of skill acquisition (i.e., final summative skill assessment); 3) student perception of skill performance on final summative assessment; 4) standardized patient perception of skill performance on summative assessment; 5) student perception of the utility of the standardized patient (SP) simulation activity in training towards skill acquisition in this practice area, and 6) post-implementation reflection from students working with PWA in their second semester.

Training Students. Students completed a residential course focused on the nature, assessment and treatment of aphasia. Following content related to the definition of aphasia and its main characteristics, students were introduced to assessment methods. Specific to building skills in screening and assessment procedures, the following hands-on activities were designed and implemented across an eight-week period to foster knowledge and skill development:

1) Group Scoring and Analysis of the Western Aphasia Battery-Revised (WAB-R; Kertesz, 2006). A pre-recorded administration of the $W A B-R$ was used to train students on how to administer, score and interpret a standardized battery for the determination of aphasia type and severity. Written consent was obtained from the PWA for use in teaching, and students were instructed on the legal and ethical obligations for confidentiality. The instructor presented the video in short clips, using the pause feature so that students could record answers on a $W A B-R$ score sheet as the video played. Students worked in smaller groups within the scope of the larger classroom to score each section prior to advancing to the next subtest. The faculty member visited with each group as they worked through their scoring, and then the class spoke as a whole about each subtest prior to advancing to the next section. At the end of the video, students worked again in groups to determine the Aphasia Type and Aphasia Quotient. The class debriefed again, as a whole, to ensure consistency in scoring and typing. The students were then required to write a summary report of the results. The faculty member once again assisted in aspects of professional writing before the students submitted their papers for further individual feedback.

2) Live Demonstration of the Administration of the Western Aphasia Battery-Revised Bedside Screening (WAB-R-BS; Kertesz, 2006). A student volunteer administered the $W A B-R-B S$ on the faculty member during class in order to train the students in the scoring and interpretation of the $W A B-R-B S$. The faculty member's responses to the questions were taken from a transcript of a PWA who had previously been seen in the campus clinic and provided consent for her screening to be used for teaching purposes. Students worked individually to record answers as the screening unfolded. Students were allowed to work collectively in scoring the results and determining the Bedside Aphasia Score, Bedside Language Score and Bedside Aphasia Classification Criteria. The faculty member once again visited with each group as they worked through their scoring. The faculty member provided feedback and/or posed questions to facilitate learning. A class debrief was conducted to ensure consistency in scoring and interpretation of the results. The students were then required to write a summary report of the screening results with recommendations. The students submitted their papers for individual feedback from the instructor. 
3) Live Practice of the Administration of the $W A B-R-B S$. Students were required to work in pairs to each administer, score and write a report on a $W A B-R-B S$ on a peer in class. The instructor continuously monitored the room and provided individual, small group and large group instruction and guidance, as needed, for accurate administration. Students were instructed to respond naturally when being assessed, to provide an opportunity to write a report when function is typical. The instructor collected the papers and provided individual feedback on writing style.

4) Live Practice of the Administration of the WAB-R-BS on a High-Fidelity Manikin. Students worked in pairs to administer and score the $W A B-R-B S$ using a high-fidelity manikin with microphone capability. This occurred approximately halfway through the course term, following the first three activities to familiarize the students with administration, scoring and interpretation of the $W A B-R / W A B-R-B S$. Two faculty members, highly skilled and trained in the area of aphasia, served as the manikin voice-over. Responses to the questions were taken from a transcript of a PWA who had previously been seen in the campus clinic and provided consent for his screening to be used for training purposes. This simulation was conducted in the School of Nursing's Simulation Theatre, which is outfitted with two standardized hospital rooms. All aspects of a medical setting are simulated to reality. The simulation also included the Director of Simulation, a Ph.D.-level, Registered Nurse (RN) who was part of the simulation experience. She acted as the $\mathrm{RN}$ in-charge of caring for the patient. Two additional licensed and certified SLP faculty members with extensive experience with working with PWA served as the students' simulated supervisors for the exercise. They were on hand to represent a typical internship environment where the student could ask for guidance or support if they ran into challenges. As part of this simulation, students were presented with a variety of real-world challenges, including having the patient request water despite being NPO, requesting to use the bathroom despite having a catheter, and asking a series of questions over health, wellness and prognosis. Students were required to confer with their SLP supervisor following the screening to ensure accuracy of findings, and then follow-up with the RN to provide results and recommendations for patient care. They were also required to chart a brief summary of the findings in a medical record. Students were engaged in a debriefing session following the simulation with the two faculty "patients," two faculty "SLP medical site supervisors" and the faculty "RN." Debriefing included having the students share successes, challenges and take-home points; and providing the students with feedback on the same from the perspective of the patient, supervisor and RN. Students completed a 5-point Likert scale survey on the utility of the simulation towards learning outcomes.

5) Repeat Step 2 (Above). Students were once again led through the scoring and interpretation of an administration of the $W A B-R-B S$ as in Step 2 above.

6) Repeat Step 3 (Above): Students were again required to administer, score and write a report on a $W A B-R-B S$ on a second peer in class. This time, the students were asked to simulate the performance of a PWA. Students were instructed to perform in a manner consistent with the specific Aphasia Type and Severity that they had elected to portray. This was also an exercise in having the students think critically about the features of aphasia that they learned across the course of the class. A guest speaker with aphasia provided a model for students to consider portraying. The primary faculty member for the course walked around the room to ensure appropriateness and consistency of behaviors with the given profile. Suggestions were made as appropriate.

7) Final Summative Skills Assessment. Students were required to complete a final assessment of their skill development using the $W A B-R-B S$ on a trained SP. The primary faculty member in the 
content area developed a case profile for a PWA with an accompanying transcript of the full administration of the $W A B-R-B S$. Students were required to obtain a focused case history, accurately administer the $W A B-R-B S$, provide oral education to the patient, accurately score the $W A B-R-B S$ and complete written reporting functions. The first three components were scored by a trained supervisor, during the Final Summative Skills Assessment; while the scoring and written reporting functions were graded by the primary faculty member for the course after submission of the summary report. Students were required to complete a self-reflection over their summative skills performance. This was a 5-point Likert scale that included components of success towards obtaining a case history, administering the assessment battery, scoring the assessment battery, and professionalism. Students were also required to complete a post-simulation reflection two days after the final summative skills assessment to evaluate the utility of the activity in facilitating development of skills in this content area. This was also a 5-point Likert scale that included a section for open-ended comments.

8) 3-Month Post-Implementation Reflection from Students Working with PWA. A total of 12 of the 36 students who originally participated in the simulation had first-year clinical practice placements with PWA. These 12 students were asked to complete a 3-month post-implementation self-reflection to examine the impact of the simulation of their confidence surrounding a number of clinical functions.

Students were continuously monitored and guided by the primary course instructor during exercises 1-6, while they were in the formative assessment period (i.e., acquisition of skills phase). Work was collected to gauge knowledge and skill development, and feedback was provided for growth and implementation towards the final summative skill assessment. Grades were not assigned during the formative task activities, as the purpose was to provide a low stress environment in which to teach and train skills. Students were encouraged to work collaboratively with one another and the instructor. Students were only assigned grades on the final summative assessment (\#7), which measured competency towards skill acquisition/clinical practice in this area.

Standardized Patients. An SP training guide was created to ensure standardization of the patient profile and simulation procedure across subjects and students. The primary faculty member in the content area developed a fictional PWA based on a modification from a real PWA from past clinical experience. The manual opened with a description of the patient profile with past medical history, social history, and current circumstance. Videos were provided for the SP to be able to see the nature of aphasia. Videos were carefully selected as to provide examples of aphasia that were similar in type and severity to the case profile that the SP would be enacting.

The second section of the manual outlined the role of the SP in providing an appropriate and accurate portrayal of the described patient's characteristics and emotional tone, and in observing and rating the students' behavior on a performance checklist from the patient's perspective. The third section of the manual included specific instruction on every aspect of how the SP was to answer and behave on each individual question that would be asked on the screening. Each question from the $W A B-R-B S$ was presented in a bold font, with a verbatim response that was expected of the SP. Instructions were also given regarding open-ended questions or other questions that were not part of the screening procedures.

The SPs were brought into the clinic where the final summative assessment was to be conducted for training and to familiarize them with the setting. An in-depth training of the SPs was conducted 
by the primary faculty member and included review of the $W A B-R-B S$, the SP manual and the performance checklist. SPs were then asked to go home and review the linked videos and practice their scripts. One week later, the SPs returned and completed a dry-run of the script with secondyear students who volunteered to provide them with feedback and guidance on their representation of the SP case. The primary faculty member also visited each of the SPs to provide feedback on their portrayal of the patient. A debrief was completed to ensure all SPs were comfortable and ready to proceed with the final summative skills assessment.

Supervisors. A supervisor training guide was created to ensure consistency in student assessment. The primary faculty member in the content area developed the training guide, which included the patient's past medical history, social history and current circumstances. This was identical to what was given to the SPs for training. The supervisors were provided with a copy of the SP manual for review in order to know how the patient was expected to respond to each question and what the student should discuss with the supervisor post-assessment before providing results and recommendations to the patient. The guide included a description of the expected Bedside Aphasia Score, Bedside Language Score and Bedside Aphasia Classification Criteria for the given patient. The final section of the guide explained the expectations of the supervisor's role in the clinic room, during the post-assessment conferral, and in the post-final summative skills debrief. The supervisors were instructed that their role was to observe, take notes and score the students' performance based on the Final Summative Skills Assessment Rubric. The notes were used in the post-assessment debrief. Supervisors were instructed to assist the student, if needed, as they would in a clinical setting; but to score on independent performance on the assessment rubric. This was intended to decrease stress during the assessment. It was felt that supporting the student, if they experienced challenges, would prevent a spiral effect on subsequent performance measures within the final summative skills assessment. Supervisors were also instructed to guide the students, if they got off track, during the post-assessment conferral as to ensure that the students provided accurate results and recommendations to the patient. Again, scoring was made according to the student's accuracy in independent performance. Finally, supervisors were instructed to provide the students with feedback during a 5-minute debrief following the final summative skills assessment. This was completed to provide the students with immediate input on their skills for learning purposes.

The supervisors were brought into the clinic for training on the patient case, the supervisor's expected role and the evaluation rubric. All of the supervisors were California licensed and American Speech-Language-Hearing Association certified (CCC-SLP). All supervisors also had extensive experience in supervision of graduate students, clinical service provision of PWA, and the use of simulation for training of clinical skills. All of the supervisors were skilled and familiar with the use of rubrics to assess summative skills. The supervisors were present in the room for the entire administration of the $W A B-R-B S$, and were responsible to score the students on the assessment rubric based on their direct observations. The supervisor and student stepped out of the room to consult on the results prior to the student's provision of oral education to the patient.

Data Analysis. Descriptive statistics were used to report data. Researchers used Microsoft Excel(C) to calculate range, means and percentages for student skill acquisition. Percentages were analyzed to describe data on the 5-point Likert scale surveys. Means on the perception surveys from graduate students and SPs were compared by performing a t-test through Microsoft ExcelC. 


\section{Results}

High-Fidelity Manikin (HFM) Simulation. Students were asked to complete a 5-point Likert scale survey over the utility of the HFM simulation to train various clinical skills (Table 1). A total of 35 students participated in this activity. One student was unable to complete the survey due to an extended absence. Overall, students strongly agreed that the simulation was effective in facilitating their skill development. One hundred percent $(100 \%)$ of the students strongly agreed that "relevant teaching points were reviewed in the debriefing session," that they were "challenged to perform at their highest potential during the simulation" and that "the simulation learning activity gave them the opportunity to use clinical judgment." Ninety-seven percent (97\%) of students strongly agreed that "they clearly understood the purpose of the simulation," that "cues were provided to promote their understanding during the simulation," and that "they were able to reflect on their performance during debriefing." Students ranked all components of the survey as strongly agreed or agree with the exception of three items. The fewest number of students strongly agreed that "they were able to effectively take data while attending to the patient" (49\%), that "they were able to problem solve any difficult moments" $(35 \%)$, and that "they felt confident that they would be able to handle 'this' situation in real life" (41\%). Nine (9\%) percent of students disagreed that "they were able to effectively take data while attending to the patient," while three (3\%) percent disagreed that "they were able to problem solve any difficult moments" and "that they feel confident that they would be able to handle this 'situation' in real life." The remaining students agreed to these survey items.

Student Perceptions of Skill Performance. Students were given a 5-point Likert scale survey to reflect on how they felt they performed on the final summative skills assessment (Table 2). Overall, the majority of students felt they performed very good across all measures with the exception of "obtaining a focused case history" (only 39\% indicated very good performance) and "effectively explaining the procedures and purpose of the assessment" (only 36\% indicated very good performance). The majority of students ranked themselves as needs improvement on these two measures. Less than twenty-five (25\%) of students ranked themselves as needs improvement on the remaining ten items. On five of the measures, a small percentage of students ranked their performance as marginal or unacceptable. Specifically, between 3-6\% of students perceived marginal to unacceptable performance in "obtaining a focused case history," "asking questions over communication difficulties," "asking questions over personal goals," "effectively explaining results in terms that the patient could understand," and in "prompting the client for questions." Between $5 \%$ and $20 \%$ of students rated themselves as outstanding across the measures. Nineteen (19\%) percent of students felt they performed outstanding on "asking questions over personal goals," "interacting with a professional demeanor," and "listening openly to the client." 
Table 1. Percentage of students' ratings $(n=35)$ of the utility of the High-Fidelity Manikin (HFM) simulation using a 5-point Likert scale survey.

\begin{tabular}{|c|c|c|c|c|c|}
\hline $\begin{array}{l}\text { Rate how this simulation helped } \\
\text { you move toward mastery of } \\
\text { these learner outcomes: }\end{array}$ & $\begin{array}{l}\text { Strongly } \\
\text { Agree }\end{array}$ & Agree & $\begin{array}{c}\text { Not } \\
\text { Applicable }\end{array}$ & Disagree & $\begin{array}{l}\text { Strongly } \\
\text { Disagree }\end{array}$ \\
\hline Managing the environment & $88 \%$ & $12 \%$ & $0 \%$ & $0 \%$ & $0 \%$ \\
\hline Identify relevant data & $88 \%$ & $12 \%$ & $0 \%$ & $0 \%$ & $0 \%$ \\
\hline $\begin{array}{l}\text { Determine appropriate course of } \\
\text { action }\end{array}$ & $88 \%$ & $12 \%$ & $0 \%$ & $0 \%$ & $0 \%$ \\
\hline Prioritize interventions & $72 \%$ & $28 \%$ & $0 \%$ & $0 \%$ & $0 \%$ \\
\hline Communicate effectively & $86 \%$ & $14 \%$ & $0 \%$ & $0 \%$ & $0 \%$ \\
\hline \multicolumn{6}{|l|}{ Rate the following statements: } \\
\hline $\begin{array}{l}\text { I clearly understood the purpose of } \\
\text { the simulation }\end{array}$ & $97 \%$ & $3 \%$ & $0 \%$ & $0 \%$ & $0 \%$ \\
\hline $\begin{array}{l}\text { Cues were provided to promote } \\
\text { my understanding during the } \\
\text { simulation }\end{array}$ & $97 \%$ & $3 \%$ & $0 \%$ & $0 \%$ & $0 \%$ \\
\hline $\begin{array}{l}\text { I was able to effectively take data } \\
\text { while attending to the patient }\end{array}$ & $49 \%$ & $42 \%$ & $0 \%$ & $9 \%$ & $0 \%$ \\
\hline $\begin{array}{l}\text { I was able to problem solve any } \\
\text { difficult moments }\end{array}$ & $35 \%$ & $62 \%$ & $0 \%$ & $3 \%$ & $0 \%$ \\
\hline $\begin{array}{l}\text { The scenario resembled a real life } \\
\text { situation }\end{array}$ & $91 \%$ & $9 \%$ & $0 \%$ & $0 \%$ & $0 \%$ \\
\hline $\begin{array}{l}\text { Relevant teaching points were } \\
\text { reviewed in the debriefing session }\end{array}$ & $100 \%$ & $0 \%$ & $0 \%$ & $0 \%$ & $0 \%$ \\
\hline $\begin{array}{l}\text { I was able to reflect on my } \\
\text { performance during debriefing }\end{array}$ & $97 \%$ & $3 \%$ & $0 \%$ & $0 \%$ & $0 \%$ \\
\hline $\begin{array}{l}\text { I responded to cues during the } \\
\text { simulation in a timely manner }\end{array}$ & $58 \%$ & $42 \%$ & $0 \%$ & $0 \%$ & $0 \%$ \\
\hline $\begin{array}{l}\text { This situation offered a variety of } \\
\text { ways to learn the material }\end{array}$ & $88 \%$ & $12 \%$ & $0 \%$ & $0 \%$ & $0 \%$ \\
\hline $\begin{array}{l}\text { The roles for the simulation were } \\
\text { understandable }\end{array}$ & $88 \%$ & $12 \%$ & $0 \%$ & $0 \%$ & $0 \%$ \\
\hline I learned from my peers & $91 \%$ & $9 \%$ & $0 \%$ & $0 \%$ & $0 \%$ \\
\hline $\begin{array}{l}\text { I was challenged to perform at my } \\
\text { highest potential during the } \\
\text { simulation }\end{array}$ & $100 \%$ & $0 \%$ & $0 \%$ & $0 \%$ & $0 \%$ \\
\hline $\begin{array}{l}\text { I feel confident that I will be able } \\
\text { to handle this "situation" in real } \\
\text { life }\end{array}$ & $41 \%$ & $56 \%$ & $0 \%$ & $3 \%$ & $0 \%$ \\
\hline $\begin{array}{l}\text { This simulation learning activity } \\
\text { gave me the opportunity to use } \\
\text { clinical judgment }\end{array}$ & $100 \%$ & $0 \%$ & $0 \%$ & $0 \%$ & $0 \%$ \\
\hline
\end{tabular}


Table 2. Students' reflections $(n=36)$ of performance on the final summative skills assessment using a 5-point Likert scale survey.

\begin{tabular}{|c|c|c|c|c|c|}
\hline & $\begin{array}{c}5- \\
\text { Outstanding }\end{array}$ & $\begin{array}{c}\text { 4- } \\
\text { Very } \\
\text { Good } \\
\end{array}$ & $\begin{array}{c}\text { 3- } \\
\text { Needs } \\
\text { Improvement }\end{array}$ & $\begin{array}{c}2- \\
\text { Marginal }\end{array}$ & $\begin{array}{c}1- \\
\text { Unacceptable }\end{array}$ \\
\hline $\begin{array}{l}\text { Introduced } \\
\text { self/made client } \\
\text { feel comfortable }\end{array}$ & $11 \%$ & $75 \%$ & $14 \%$ & $0 \%$ & $0 \%$ \\
\hline $\begin{array}{l}\text { Questions over } \\
\text { past medical } \\
\text { history }\end{array}$ & $8 \%$ & $39 \%$ & $50 \%$ & $0 \%$ & $3 \%$ \\
\hline $\begin{array}{l}\text { Questions over } \\
\text { communication }\end{array}$ & $6 \%$ & $69 \%$ & $22 \%$ & $3 \%$ & $0 \%$ \\
\hline $\begin{array}{l}\text { Questions over } \\
\text { goals }\end{array}$ & $19 \%$ & $64 \%$ & $11 \%$ & $3 \%$ & $3 \%$ \\
\hline $\begin{array}{l}\text { Effective } \\
\text { explanations of } \\
\text { procedures/purpose }\end{array}$ & $8 \%$ & $36 \% *$ & $53 \%$ & $0 \%$ & $0 \%$ \\
\hline $\begin{array}{l}\text { Effective } \\
\text { administration of } \\
\text { subtests }\end{array}$ & $11 \%$ & $72 \%$ & $17 \%$ & $0 \%$ & $0 \%$ \\
\hline $\begin{array}{l}\text { Effective scoring } \\
\text { of subtests }\end{array}$ & $6 \%$ & $75 \%$ & $17 \% * *$ & $0 \%$ & $0 \%$ \\
\hline $\begin{array}{l}\text { Wrote a } \\
\text { clear/concise } \\
\text { report }\end{array}$ & $8 \%$ & $67 \%$ & $22 \% * *$ & $0 \%$ & $0 \%$ \\
\hline $\begin{array}{l}\text { Effectively shared } \\
\text { results in layman's } \\
\text { terms }\end{array}$ & $14 \%$ & $58 \%$ & $19 \% * *$ & $6 \%$ & $0 \%$ \\
\hline $\begin{array}{l}\text { Professional } \\
\text { interaction }\end{array}$ & $19 \%$ & $72 \% *$ & $6 \%$ & $0 \%$ & $0 \%$ \\
\hline $\begin{array}{l}\text { Prompted client for } \\
\text { questions }\end{array}$ & $17 \%$ & $61 \%$ & $17 \%$ & $6 \%$ & $0 \%$ \\
\hline Listened openly & $19 \%$ & $75 \%$ & $3 \% * *$ & $0 \%$ & $0 \%$ \\
\hline
\end{tabular}

* 1 student rated a 4.5

** 1 student rated a 3.5

Standardized Patients' Perceptions of Skill Performance. The SPs were given a 5-point Likert scale survey immediately following each student visit to reflect on how they felt the student performed on the final summative skills assessment (Table 3). One standardized patient did not complete a survey on one of the students $(n=35)$. Overall, the majority of SPs felt the students performed very good across all measures without exception. A t-test comparing means between SPs and students revealed higher percentages for SPs in comparison to the students' percentages. One mean was statically significant and that item was "obtaining a focused case history." SPs rated students significantly higher than students rated themselves $(p=.0057)$. None of the SPs gave rankings of marginal or unacceptable for any measure, which again reflects a perception of greater 
student competency on the part of the SP as compared to the students themselves. The SPs gave higher ratings than the students on "obtaining a focused case history" (39\% of students rated themselves as very good while $86 \%$ of the SPs rated the students as very good); "questions over communication difficulties" (69\% of students rated themselves as very good while $91 \%$ of the SPs rated the students as very good); and "explanations over procedures and purpose of assessment" (36\% of students rated themselves as very good while $61 \%$ of the SPs rated the students as very good). A larger percentage of students rated themselves as outstanding than did their SPs on six of the nine common measures. Of particular note, $19 \%$ of students rated themselves as outstanding on "asking questions over patient goals" while only $11 \%$ of SPs found the students outstanding; $17 \%$ of students rated themselves as outstanding on "prompting the client to ask questions" while only $6 \%$ of SPs found the students outstanding; and 19\% of students rated themselves as outstanding on "listening openly" while only $9 \%$ of SPs found the students outstanding.

Table 3. Standardized patients' reflections $(n=35)$ of student performance on the final summative skills assessment using a 5-point Likert scale survey.

\begin{tabular}{|c|c|c|c|c|c|}
\hline & $\begin{array}{c}\text { 5- } \\
\text { Outstanding }\end{array}$ & $\begin{array}{c}\text { 4- } \\
\text { Very } \\
\text { Good } \\
\end{array}$ & $\begin{array}{c}\text { 3- } \\
\text { Needs } \\
\text { Improvement }\end{array}$ & $\begin{array}{c}\text { 2- } \\
\text { Marginal }\end{array}$ & $\begin{array}{c}1- \\
\text { Unacceptable }\end{array}$ \\
\hline $\begin{array}{l}\text { Introduced } \\
\text { self/made client } \\
\text { feel comfortable }\end{array}$ & $17 \%$ & $66 \%$ & $14 \% *$ & $0 \%$ & $0 \%$ \\
\hline $\begin{array}{l}\text { Questions over } \\
\text { past medical } \\
\text { history }\end{array}$ & $3 \%$ & $86 \%$ & $11 \%$ & $0 \%$ & $0 \%$ \\
\hline $\begin{array}{l}\text { Questions over } \\
\text { communication }\end{array}$ & $3 \%$ & $91 \%$ & $6 \%$ & $0 \%$ & $0 \%$ \\
\hline $\begin{array}{l}\text { Questions over } \\
\text { goals }\end{array}$ & $11 \%$ & $77 \%$ & $11 \%$ & $0 \%$ & $0 \%$ \\
\hline $\begin{array}{l}\text { Effective } \\
\text { explanations of } \\
\text { procedures/purpose }\end{array}$ & $6 \%$ & $61 \%$ & $25 \% * *$ & $0 \%$ & $0 \%$ \\
\hline $\begin{array}{l}\text { Effectively shared } \\
\text { results in layman's } \\
\text { terms }\end{array}$ & $20 \%$ & $66 \%$ & $11 \% *$ & $0 \%$ & $0 \%$ \\
\hline $\begin{array}{l}\text { Professional } \\
\text { interaction }\end{array}$ & $23 \%$ & $71 \%$ & $3 \% *$ & $0 \%$ & $0 \%$ \\
\hline $\begin{array}{l}\text { Prompted client for } \\
\text { questions }\end{array}$ & $6 \%$ & $80 \%$ & $11 \% *$ & $0 \%$ & $0 \%$ \\
\hline Listened openly & $9 \%$ & $91 \%$ & $0 \%$ & $0 \%$ & $0 \%$ \\
\hline
\end{tabular}

* 1 standardized patient rated a 3.5

** 2 standardized patients rated a 3.5

Note: one survey was not completed.

Standardized Patients (SP) Simulation. Students were asked to complete a 5-point Likert scale survey over the utility of the SP simulation to facilitate development of various clinical skills (Table 4). A total of 35 students completed this survey. 
Overall, the majority of students felt the simulation facilitated their learning extremely well on all measurements with the exception of "establishing rapport with the patient." Ninety-four percent (94\%) of the students indicated that they "understood the purpose of the simulation" extremely well. Eighty-six percent $(86 \%)$ of the students indicated that the simulation "promoted their understanding of screening administration" extremely well. Students gave lower rankings overall to "establishing rapport with the client" (26\% rated extremely well); "pacing the assessment" (54\% rated extremely well); "problem solving difficult moments" (54\% rated extremely well); and "modifying based on client status" (57\% rated extremely well). There were four items for which students noted limited or not at all performance. These were "establishing rapport with the client," "pacing the assessment," "problem solving difficult moments," and "providing results of the evaluation." Students gave the lowest percentage of performance on "establishing rapport with the client." A total of $17 \%$ of the students noted that they had either limited or not at all ability to establish rapport.

Table 4. Students' ratings $(n=35)$ of the utility of the standardized patient simulation using a 5point Likert scale survey (Note: one survey was not completed).

\begin{tabular}{|c|c|c|c|c|c|}
\hline $\begin{array}{l}\text { How well did this } \\
\text { simulation facilitate my } \\
\text { learning outcomes } \\
\text { related to the following } \\
\text { skills: }\end{array}$ & $\begin{array}{c}5- \\
\text { Extremely } \\
\text { Well }\end{array}$ & $\begin{array}{c}\text { 4- } \\
\text { Moderately } \\
\text { Well }\end{array}$ & $\begin{array}{c}\text { 3- } \\
\text { Adequate }\end{array}$ & $\begin{array}{c}\text { 2- } \\
\text { Limited }\end{array}$ & $\begin{array}{c}\text { 1- } \\
\text { Not At } \\
\text { All }\end{array}$ \\
\hline $\begin{array}{l}\text { Understanding the purpose } \\
\text { of the simulation }\end{array}$ & $94 \%$ & $3 \%$ & $3 \%$ & $0 \%$ & $0 \%$ \\
\hline $\begin{array}{l}\text { Establishing rapport } \mathrm{w} / \mathrm{a} \\
\text { client }\end{array}$ & $26 \%$ & $34 \%$ & $23 \%$ & $14 \%$ & $3 \%$ \\
\hline $\begin{array}{l}\text { Managing the } \\
\text { Environment }\end{array}$ & $60 \%$ & $26 \%$ & $14 \%$ & $0 \%$ & $0 \%$ \\
\hline $\begin{array}{l}\text { Promoting my } \\
\text { understanding of } \\
\text { screening administration }\end{array}$ & $86 \%$ & $14 \%$ & $0 \%$ & $0 \%$ & $0 \%$ \\
\hline Pacing the assessment & $54 \%$ & $37 \%$ & $6 \%$ & $3 \%$ & $0 \%$ \\
\hline $\begin{array}{l}\text { Taking data while } \\
\text { attending to the client }\end{array}$ & $69 \%$ & $29 \%$ & $3 \%$ & $0 \%$ & $0 \%$ \\
\hline $\begin{array}{l}\text { Problem solving difficult } \\
\text { moments }\end{array}$ & $54 \%$ & $26 \%$ & $17 \%$ & $3 \%$ & $0 \%$ \\
\hline $\begin{array}{l}\text { Modifying based on client } \\
\text { status }\end{array}$ & $57 \%$ & $31 \%$ & $11 \%$ & $0 \%$ & $0 \%$ \\
\hline $\begin{array}{l}\text { Developing a summary of } \\
\text { findings to convey to the } \\
\text { client }\end{array}$ & $66 \%$ & $34 \%$ & $0 \%$ & $0 \%$ & $0 \%$ \\
\hline $\begin{array}{l}\text { Providing results of an } \\
\text { evaluation }\end{array}$ & $69 \%$ & $29 \%$ & $0 \%$ & $3 \%$ & $0 \%$ \\
\hline
\end{tabular}


Post-Implementation Simulation. Twelve graduate students responded to open-ended questions on the self-reflection post simulation. These students currently work with PWAs. The open-ended responses were reviewed and the following main themes were evident. Students overall reported that they felt more "comfortable" and "confident" in conducting assessments following the HFM and standardized patient simulation with a PWA. There was also a general consensus that the experiences were very valuable and assisted the students in adapting to tasks and client needs (e.g., pace of session; timing). Students noted that they absolutely "love" simulation because it gives them a low-pressure way to gain familiarity with communication disorder profiles.

\section{Discussion}

This descriptive study aimed to investigate the utility of simulation methodology in facilitating skill acquisition and perception of competency in graduate students of SLP in screening for PWA in an academic setting. Students were trained on each of the performance elements during their scheduled course time, under the direction of the primary content area faculty member. A final summative assessment was completed to measure student competency in screening for aphasia. Data was collected from supervisors, student surveys and SP surveys. Analysis reflected high overall scores on all measures. The mean score for the final summative assessment was a 39.5, with a range of 37-40. This mean reflects a near ceiling performance across students. This was to be expected as the students were directly taught the mechanics of performing a language screening, and then given multiple opportunities to practice that specific clinical skill. As per supervisory input, areas of greatest improvement in student performance included "inquiring if the patient had questions" and "obtaining a focused case history." Interestingly, the student survey data also reflected lower performance scores on "obtaining a focused case history," suggestive of the fact that students were aware of the need for improvement on this clinical skill. The rubric was primarily built on performance of concrete clinical tasks vs. interpersonal dynamics. As well, practice during the various training experiences was geared towards the clinical mechanics of administering a language screening vs. professional practice interaction and personal qualities.

By and large, students rated their performance on the final summative skill assessment as very good across all 12 measures. As noted above, the students indicated greater difficulty with "obtaining a focused case history" and "effectively explaining the procedures and purpose of the aphasia assessment to the client." While the students may have felt that they were challenged to explain the aphasia assessment procedures, the SPs and supervisors gave higher ratings on this item. A small percentage of students (3-6\%) rated their skills as marginal or unacceptable on five of the items. Students felt they could improve upon their ability to ask questions and explain procedures. These findings are consistent with literature published on graduate student perceptions and competency in working with PWA. Finch and colleagues (2013) found that students who received coursework, but not clinical placements with PWA did not feel confident in their skills in working with PWA. Zraick et al. (2003) found that while students demonstrated competency in the clinical mechanics of evaluations, they struggled overall with interpersonal communication skills with PWA. Findings from the current study are consistent with previous literature and highlight the need for an expanded simulation curriculum that includes opportunities to practice communication skills, such as building rapport, collecting a case history and managing conversational dynamics.

A slightly larger percentage of students (5-19\%) rated themselves as outstanding across three items. These items reflected higher scores for items related to professionalism and open listening. 
Interestingly, a larger percentage of students rated themselves as outstanding on six of the nine common measures, as compared to the SPs. While students ranked themselves high on open listening, the SPs gave them overall lower scores. SPs also ranked the students lower on inquiring about personal goals and prompting the client for questions.

Students had an overall positive impression of the utility of the simulations to facilitate their skill acquisition. One-hundred percent (100\%) of students strongly agreed that the simulation debrief contained relevant teaching points, while $97 \%$ strongly agreed that they understood the purpose of the simulation. The data also showed that students found it difficult to collect information while attending to the patient and problem solve difficult situations in real-time. This finding did not surprise the researchers as it requires multi-tasking, higher level critical thinking, and experience. Surprisingly, students felt the least confident about establishing a relationship with the patient. The researchers attributed this to the fact that the patient's stroke profile limited their communicative abilities, resulting in greater responsibility for the student to lead and direct communication.

\section{Conclusions}

There was an overall positive response to the use of simulation to facilitate skill building in working with PWA. Students' perceptions largely matched that of supervisors and SPs. Students also excelled in the final summative skill assessment activity, reflecting a high level of competency in screening PWA. All participants felt that the activities were worthwhile and requested further simulation activities towards building competencies.

One noted limitation was that the SPs were as new to this procedure as the faculty. As scores from SPs were overall higher than the students, it may be indicative of inflated perceptions by the SPs. Given additional training and experience, SPs will gain greater discernment over time and the scores may adjust accordingly.

The current study has demonstrated the successful implementation of simulation methodology for the training of screening procedures in PWA for graduate students in SLP. Students overwhelmingly report positive impressions of the simulations and consistently ask to participate in more opportunities. In reflecting on the simulation post-implementation, the faculty realized that there appears to be a gap in professional interactions and interpersonal communication. This is consistent with previous literature in Communication Sciences and Disorders in working with PWA (Zraick, et al, 2003). The faculty are currently working on additional simulations to improve relational dynamics in clinical scenarios.

\section{References}

Blackburn, T., \& Sadler, C. (2003). The role of human patient simulators in health-care training. Hospital Medicine, 64(11), 677-681.

Cook, D. A., Hatala, R., Brydges, R., Zendejas, B., Szostek, J. H., Wang, A. T., ... \& Hamstra, S. J. (2011). Technology-enhanced simulation for health professions education: a systematic review and meta-analysis. JAMA, 306(9), 978-988.

Brannan, J. D., White, A., \& Bezanson, J. L. (2008). Simulator effects on cognitive skills and confidence levels. Journal of Nursing Education, 47(11), 495-500.

Council for Clinical Certification in Audiology and Speech-Language Pathology of the American Speech-Language-Hearing Association (2013). 2014 Standards for the 
Certificate of Clinical Competence in Speech-Language Pathology. Retrieved March 20, 2017 from http://www.asha.org/Certification/2014-Speech-Language-PathologyCertification-Standards/.

Decker, S., Sportsman, S., Puetz, L., \& Billings, L. (2008). The evolution of simulation and its contribution to competency. The Journal of Continuing Education in Nursing, 39(2), 7480.

Dudding, C. (2015). Full Class: Well aware of the shortage of graduate slots, the professions' leading organizations are working hard on solutions. The ASHA Leader, 20(1), 36-39.

Finch, E., Fleming, J., Brown, K., Lethlean, J., Cameron, A., \& McPhail, S. M. (2013). The confidence of speech-language pathology students regarding communicating with people with aphasia. BMC Medical Education, 13(1), 92.

Gaba, D. M. (2004). The future vision of simulation in health care. Quality and Safety in Health Care, 13(suppl 1), i2-i10.

Hill, A. E., Davidson, B. J., McAllister, S., Wright, J., \& Theodoros, D. G. (2014). Assessment of student competency in a simulated speech-language pathology clinical placement. International Journal of Speech-Language Pathology, 16(5), 464-475.

International Nursing Association for Clinical Simulation and Learning (2016). Standards of best practice: Simulation. Retrieved March 20, 2017 from http://www.inacsl.org/i4a/pages/index.cfm?pageid=3407

Kertesz, A. (2006) Western Aphasia Battery-Revised. San Antonio, TX: The Psychological Corporation.

Lasater, K. (2007). High-fidelity simulation and the development of clinical judgment: Students' experiences. Journal of Nursing Education, 46, 269-276.

Levett-Jones, T., \& Lapkin, S. (2014). A systematic review of the effectiveness of simulation debriefing in health professional education. Nurse Education Today, 34(6), e58-e63.

MacBean, N., Theodoros, D., Davidson, B., \& Hill, A. E. (2013). Simulated learning environments in speech-language pathology: An Australian response. International Journal of Speech-Language Pathology, 15(3), 345-357.

Miles, A., Friary, P., Jackson, B., Sekula, J., \& Braakhuis, A. (2016). Simulation-Based Dysphagia Training: Teaching Interprofessional Clinical Reasoning in a Hospital Environment. Dysphagia, 31(3), 407-415.

Read, J. (2014). The future of clinical education in speech and language therapy. International Journal of Therapy \& Rehabilitation, 21(11), 506-507.

Rutherford-Hemming, T. (2012). Simulation methodology in nursing education and adult learning theory. Adult Learning, 23(3), 129-137.

Seropian, M., Dillman, D., \& Farris, D. (2007). Statewide simulation systems: The next step for anesthesiology? Anesthesiology Clinics, 25(2), 271-282.

Ward, E. C., Hill, A. E., Nund, R. L., Rumbach, A. F., Walker-Smith, K., Wright, S. E., ... \& Dodrill, P. (2015). Developing clinical skills in paediatric dysphagia management using human patient simulation (HPS). International Journal of Speech-Language Pathology, 17(3), 230-240.

Zraick, R. I., Allen, R. M., \& Johnson, S. B. (2003). The use of standardized patients to teach and test interpersonal and communication skills with students in speech-language pathology. Advances in Health Sciences Education, 8(3), 237-248. 